\title{
Calotropis gigantea assisted green synthesis of nanomaterials and their applications: a review
}

Shriniwas P. Patil[D

\begin{abstract}
Background: Nanotechnology has been receiving wonderful impetus in the current emerging technological era by opening a pool of scientific ideas to compete with the daily challenges of developing technology. So far, numerous properties and countless applications of nanomaterials have been explored which have been even proved to be based on characteristic shape, size, surface area and surface chemistry.

Main content: By the time, several attempts have been made for green synthesis of nanomaterials, using plant extracts. Calotropis gigantiea (L.) R. Br is the plant belonging to Apocynaceae, have been screened and proved to possess various pharmacological activities, due to different polar phytochemicals like flavonoids, lignans and terpenoids. This review focus on phytochemicals so far reported from different parts of the plant; pharmacological activities exhibited; green synthesis of nanomaterials, particularly metallic nanoparticles green synthesised by facilitating reaction of metallic ion donor molecule/salt and aqueous extract of leaves or flowers of C. gigantiea and their biological or non-biological applications. The use of $\mathrm{C}$. gigantea in the fabrication of nanomaterials is an ecofriendly and safe approach. Secondary metabolites present act as a stabilizing agent for nanomaterials. Cadmium sulphide, titanium dioxide, nickel and nickel oxide nanoparticles synthesised using C. gigantea exerted better antimicrobial action, compared to extracts. Nanoencapsulated magnesium oxide nanoparticles avoided biochemical degradation of $\mathrm{MgO}$; increase its bioavailability and proved beneficial in type II diabetes mellitus. Cupric oxide nanoparticles got applied in dye-sensitised solar cell. Silver nanoparticles showed better cytotoxicity in HeLa cells. Biomaterial-supported zero-valent iron and stannic oxide nanoparticles proved to have utilities in water purification. Green synthesised $\mathrm{Eu}^{3+}$ doped $\mathrm{Y}_{2} \mathrm{SiO}_{5}$ nanophosphors had significant chromaticity coordinates and average correlated colour temperature, hence find application in displays.
\end{abstract}

Conclusion: Variety of nanomaterials including nanoparticles and nanophophors could successfully be biosynthesised using Calotropis gigantean extract or its latex. These green synthesised nanomaterials have several applications in the healthcare system and technology.

Keywords: Nanotechnology, Calotropis gigantea, Metal nanoparticles, Zero-valent iron nanoparticles, $\mathrm{Eu}^{3+}$ doped $\mathrm{Y}_{2} \mathrm{SiO}_{5}$ nanophosphors, Applications

Correspondence: patilsp111@gmail.com

Department of Pharmacognosy, SCES's Indira College of Pharmacy, Pune 411 038, India 


\section{Background}

Nanotechnology has gained marvellous impetus in today's rapidly emerging technological era by generating a wealth of scientific concepts to tackle with daily challenges of developing technology [1]. The nanomaterials have been proved to possess countless applications and physicochemical properties $[2,3]$ which are exerted due to their characteristic size, shape, area and surface chemistry [4]. These features of nanomaterials enable them to be highly reactive and thereby more attractive for researchers [5]. These nanomaterials may exist in the form of nanotubes, nanocrystals, nanoparticles, nanospheres, nanophosphors or even in their combination, i.e. nanohybrids. In the recent era, different metallic nanoparticles are gaining research interest in material chemistry due to their unique catalytic, electrical and optical characteristics. These nanomaterials could be conjugated with various functional biomolecules such as antibodies, ligands, and drugs of interest for biomedical applications.

\subsection{Manufacturing of nanomaterials}

Depending upon the particular type, nanomaterials can be manufactured by one of the two approaches: bottom-up and top-down. The bottom-up approach involves placing of atom by atom or molecule by molecule; which can be achieved by chemical synthesis, self-assembly and positional assembly. Top-down strategy implicates etching, milling or grinding of a larger piece of material to be converted to its nanoform. In this approach, complex devices are used, requiring high energies and producing more wastes. Hence, bottom-up strategies are preferred where atoms or molecules are get arrange themselves into ordered nano-structures by physical and/or chemical interactions.

\section{Main text}

As far as Calotropis gigantea is concerned, different research articles pertaining to a variety of aspects, right from primary microscopic features of different parts, their preliminary phytochemical evaluation, various pharmacological screening and application of its extracts in green synthesis of nanomaterials have been published. Most of these research articles are available on internationally reputed, wellrecognised search engines like ScienceDirect (http://www. sciencedirect.com), Wiley Online Library (http://onlinelibrary.wiley.com), Springer (http://linnk.springer.com), Taylor and Francis (http://www.tandfonline.com), Nature (www.nature.com) and PubMed (http://www.ncbi.nlm.nih.gov>pubmed). This review highlighted the phytochemicals reported to be present in a given part of plant Calotropis gigantea which could be claimed to be present in extract using which several successful attempts of green synthesis of nanomaterials were made. This review throws the light on the method used for their green synthesis as well as the biological/pharmacological and non-biological applications of these nanomaterials.

\subsection{Botanical description of Calotropis gigantea}

The word Calotropis was derived from the Greek word "Kalos" meaning beautiful and "tropis" meaning keel, referring to the shape of the coronal scales. Calotropis gigantea (crown flower) (Fig. 1) is a large shrub or small tree, belonging to family Asclepiadeae, characterised by the presence of a smooth and soft tomentum on stems and lower leaf surfaces, calyx lobes with many glands at the base, broadly campanulate corollas, and coronal scales with a recurved spur at the base. Among various species, this one, C. gigantea is an Asiatic, occurring widely throughout the Indian subcontinent, southern China, South East Asia and has also been introduced into New Guinea and Hawaiian islands [6].

\subsection{Phytochemical composition of Calotropis gigantea}

Over time, variety of secondary metabolites have been reported to be isolated from different parts of Calotropis gigantea and structurally elucidated.

As per Lhinhatrakool T, Sutthivaiyakit S. [7], the leaves of C. gigantea contain pinoresinol, medioresinol, uzarigenin, calotropin, calactin, calacitnic acid, calacitnic acid methyl ester, 19-carboxyl-calacitnic methyl ester, drummondol, 15b-hydroxycalotrin, the C-11 bicylic lactone, norisopenoid, the rare diphenyl furfuran lignan and

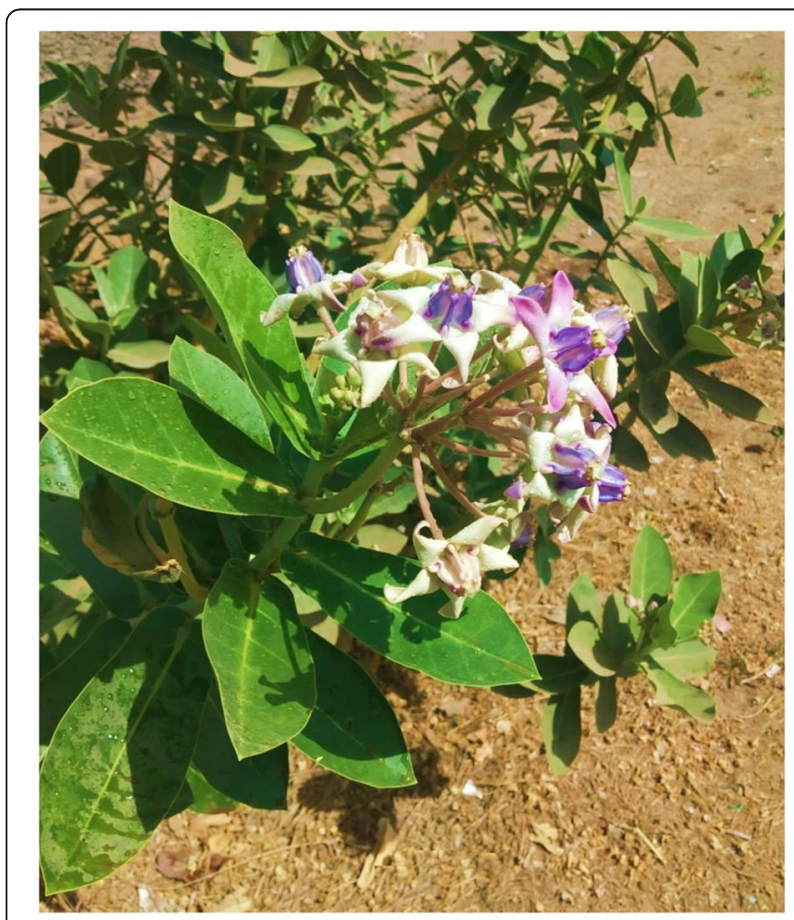

Fig. 1 Calotropis gigantea (Crown flower), belonging to family Asclepiadeae 
salicifoliol. Seeka and Sutthivaiyakit [8] isolated 15- $\beta$ Hydroxycardenolides and 16- $\alpha$-hydroxycalactinic acid methyl ester while Nguyen et al. [9] isolated a lignan, 9' methoxypinoresinol and two new glycosylated 5hydroxymethylfurfurals, calofurfuralside $\mathrm{A}$ and calofurfuralside B from the leaves of C. gigantea. Di-(2-ethylhexyl) Phthalate and anhydrosophoradiol-3-acetate were isolated from flower [10]. Sen et al. [11] isolated flavonol glycosides, isorhamnetin-3-0-[2-O- $\beta$-D-galactopyranosyl-6-O- $\alpha-\mathrm{L}$-rhamnopyranosyl] $-\beta$-D-glucopyranoside, isorhamnetin-3-O-rutinoside, isorhamnetin-3-0-glucopyranoside and taraxasteryl acetate from aerial parts of $C$. gigantea. The fixed oil separated from seeds of $C$. gigantea was reported to contain lauric acid, myristic acid, palmitic acid, palmitoleic acid, stearic acid, oleic acid, linoleic acid, linolenic acid, arachidic acid and behenic acid (book chapter). These fatty acids are also present in the form of mono-, di-, and tri-acyl glycerols at the surface of and internal to leaves [12]. Terpenoids derivatives like pentacyclic Triterpenic Esters and lupeoul acetate were isolated from the roots of C. gigantea [13].

\subsection{Pharmacological potential of Calotropis gigantea}

Calotropis gigantea is a notorious weed, so far not cultivated commercially. Still, the plant has been screened for different pharmacological activities, in the form of extract of any part, isolated compound or latex, using different scientifically accepted in-vivo or in-vitro models [14]. Based on phytochemicals present, different parts of Calotropis gigantea were reported to possess different pharmacological activities (Table 1).

\subsection{Green synthesis of nano-structures and their applications}

Several researchers tested the hypothesis which was based on nanostructures if synthesised using C. gigantea or its latex, could have improvement in pharmacological potential exhibited by different extracts prepared using different parts of C. gigantea or latex collected; or else, these nanomaterials could be used in non-biological applications like those in the field of energy or television displays (LEDs and LCDs).

\subsection{Cadmium sulphide nanoparticles}

In 2017, Ayodhya and Veerabhadram [29] synthesised cadmium sulphide nanoparticles using aqueous extract of leaves of C. gigantea. The extract was further mixed with $40 \mathrm{~mL}$ of $1 \mathrm{mM}$ of cadmium acetate and $40 \mathrm{~mL}$ of $1 \mathrm{mM}$ of sodium sulphide to obtain spherical CdS NPs. CdS NPs were then characterised for their morphology, stability and particle size; photocatalytic activity was studied under sunlight irradiation using $\mathrm{MB}$ and $\mathrm{EY}$ dyes. The XRD pattern of CDs NPs exhibited three prominent peaks at $2 \theta$ values of $26.4^{\circ}, 43.4^{\circ}$ and $51.6^{\circ}$;

Table 1 Pharmacological activities of C.gigantea

\begin{tabular}{|c|c|c|c|}
\hline $\begin{array}{l}\text { Part of } \\
\text { plant }\end{array}$ & Pharmacological Activity & Pharmacological model used & Reference \\
\hline Flowers & Analgesic & Acetic acid induced writhing & [15] \\
\hline Flowers & Anti-tumoric & Ehrlich's ascites carcinoma in mice & [16] \\
\hline Latex & Antibacterial & Agar well diffusion method using cariogenic bacteria & [17] \\
\hline Leaves & Antibacterial & Agar well diffusion method using Klebsiella spp & [18] \\
\hline Flowers & Anti-fungal & Disc diffusion assay method using Aspergillus flavus and Aspergillus fumigatus & [10] \\
\hline Flowers & Cytotoxicity & Brine shrimp lethality bioassay & \\
\hline $\begin{array}{l}\text { Aerial } \\
\text { parts }\end{array}$ & Antipyretic & $\begin{array}{l}\text { TAB (typhoid) vaccine-induced pyrexia in rabbits and Brewer's yeast-induced pyrexia in } \\
\text { rats }\end{array}$ & [19] \\
\hline Root bark & Antitumour & Ehrlich's ascites carcinoma in mice & [20] \\
\hline $\begin{array}{l}\text { Peeled } \\
\text { roots }\end{array}$ & $\begin{array}{l}\text { Anticonvulsant and skeletal } \\
\text { muscle relaxant activity }\end{array}$ & Pentobarbitone-induced sleeping time model and rotating rod model & [21] \\
\hline Leaves & $\begin{array}{l}\text { Anticonvulsant and skeletal } \\
\text { muscle relaxant activity }\end{array}$ & $\begin{array}{l}\text { Maximal electroshock seizure (MES) and Strychnine-induced convulsions models and } \\
\text { rotating rod model }\end{array}$ & [22] \\
\hline Leaves & Cytostatic and cytotoxic activity & $\begin{array}{l}\text { SRB assay using tumour cell lines: MDA-MB-231 (human breast cancer), PC-3 } \\
\text { (human prostate cancer), MCF7 (human breast cancer), HT-29 (human colon cancer), 4T1 } \\
\text { (mouse mammary cancer), and RAW-267 (mouse leukemic monocyte macrophage) }\end{array}$ & [23] \\
\hline Leaves & Antiplasmodial & Lactate dehydrogenase assay using human blood & [24] \\
\hline $\begin{array}{l}\text { Latex and } \\
\text { fruits }\end{array}$ & HIF-1 inhibitory activities & T47D cell-based dual-luciferase reporter assay & [25] \\
\hline Root bark & Wound healing & Excision, incision and dead space wound models & [26] \\
\hline Roots & Pregnancy interception & Postcoital contraceptive efficacy evaluation & [27] \\
\hline Latex & Procoagulant activity & Re-calcification time and fibrinogenolytic activity & [28] \\
\hline
\end{tabular}


corresponding to the (111), (220) and (311) diffraction planes of cubic crystals. The average particle size of $\mathrm{CdS}$ NPs was found to be $12 \mathrm{~nm}$. The nanophase and quantum confinement nature of the synthesised CdS NPs was indicated by enhancement of the optical band gap of $2.42 \mathrm{eV}$. It was also observed that as in particle size decreases, the energy of separation between the ground and excited electronic states increases; resulting in a blue shift in absorption. The capping effects and functional groups of $C$. gigantea leaf extract phytochemicals on CdS NPs surfaces were investigated by ATRFTIR. The longevity of CdS NPs was tested by recycling the photocatalyst used in the photocatalytic degradation of MB and EY dyes under 60 min of sunlight irradiation. The result indicated that the $\mathrm{CdS}$ catalysts are fairly photostable and practically applicable. It was claimed that electron-donating functional groups of phytochemical present in aqueous extract of C. gigantea leaves are responsible for the stability of CdS NPs and the reduction of both dyes. Further, CdS NPs were evaluated for antimicrobial activity and compared with that exerted by core C. gigantea leaves extract. In the culture of bacteria, E. coli, $P$. aeruginosa, S. aureus and B. thuringiensis; and fungi, $A$. niger and $C$. albicans; zone of inhibition obtained with CdS NPs were 4 to 6 times wider than those obtained with C.gigantea leaves extract. About antifungal activity, it was claimed that CDs NPs got saturated and adhered to fungal hypha and to disrupt them.

\subsection{Magnesium oxide nanoparticles}

As such oral magnesium supplements are consumed to increase insulin sensitivity and reducing the risk of the onset of type 2 diabetes. This is because magnesium is an important co-factor/prosthetic group for phosphorylation causing enzymes like tyrosine-kinase, playing a significant role in insulin signalling pathway. But commonly available supplement, magnesium oxide, $\mathrm{MgO}$ has poor oral bioavailability and thereby may get decomposed by gastric acid. Hence, with the hypothesis that nanoencapsulated magnesium oxide nanoparticles $(\mathrm{MgO}$ NPs) can avoid all these biochemical degradation of $\mathrm{MgO}$ and increase its bioavailability. Carried out the synthesis of MgO NPs using aqueous extract of C. gigantea and their nano-encapsulation into polymer polyvinylpyrrolidone (PVP) or Eudragit L [30]. Aqueous extract of $C$. gigantea leaves played a significant role in the formation and stabilization of MgO NPs. The MgO NPs so formed were then encapsulated by following conventional emulsion solvent evaporation method where 10 $\mathrm{mg}$ of MgO NPs and $20 \mathrm{mg}$ of PVP or $20 \mathrm{mg}$ of Eudragit $\mathrm{L}$ were dissolved in $10 \mathrm{~mL}$ of ethanol. Then, about $10 \mathrm{ml}$ of distilled water containing Tween $80(2 \%, w / w)$ or 10 $\mathrm{mL}$ liquid paraffin containing sorbitan sesquioleate $(2 \%$, $\mathrm{w} / \mathrm{w}$ ) was added as the emulsifier. Then, these mixtures were heated to $80 \mathrm{C}$ and stirred at an agitation speed of $250 \mathrm{rpm}$ on a magnetic stirrer until ethanol was fully disappeared and that nanosuspensions were centrifuged at $13200 \mathrm{rpm}$ for 20 mins to get PVP-MgO NPs or Eudragit L-MgO NPs. The average size of MgO NPs obtained was $48.38 \mathrm{~nm}$ while their crystallite size was $8 \mathrm{~nm}$. When encapsulated by emulsion solvent evaporation, PVP$\mathrm{MgO}$ NPs and Eudragit L-MgO NPs, particle size increased to 96.65 and $53.37 \mathrm{~nm}$, respectively. Eudragit L$\mathrm{MgO}$ NPs had higher stability. Drug entrapment efficiency (\%) and drug loading (\%) for Eudragit L-MgO NPs were found higher than those for PVP-MgO NPs. It was also observed that drug release pattern of Eudragit $\mathrm{L}-\mathrm{MgO}$ nanoparticles was as per Fickian diffusion mechanism and coincided well with the Weibull model.

\subsection{Nickel and nickel oxide nanoparticles}

Nickel (Ni) is the transition metal, exhibiting magnetism and catalytic properties. Nickel nanoparticles (NiNPs) have been proved to adsorb environmentally hazardous dyes and inorganic pollutants [31]. They also possess good antibacterial and anti-inflammatory activities [32]. On the other hand, its oxide form $\mathrm{NiO}$ has cubic crystal lattice structure with p-type semiconductor properties. Nanoparticles of $\mathrm{NiO}$ (NiO-NPs), due to their electron transfer capability with their own high chemical stability and super-capacitance properties [33]; they exhibit technical applications in battery cathodes, fuel cells, electrochromic films, magnetic materials, optical fibres and gas sensors [34]. Considering these potential applications, Din et al. [35] fabricated Ni-NPs and NiO-NPs using hydromethanolic ( $40 \%$ methanol) extract of freshly collected leaves of C. gigantea. In UV/vis spectrum, sharp exciton absorption was positioned at $415 \mathrm{~nm}$, suggested that $C$. gigantea extract assisted green synthesised NiO NPs were stable. The FT-IR spectra of both Ni and NiO NPs did not show a peak around $1000-1100 \mathrm{~cm}^{-1}$ while peak for $\mathrm{O}-\mathrm{H}$ bond got reduced in Ni NPs FTIR spectrum and almost completely reduced in NiO NPs FTIR spectrum; suggesting the important role of alcohols and halogens in metal ion reduction. Amines also played role as a capping agent in the fabrication of Ni-NPs. As per the results of XRDanalysis the particle size of Ni-NPs was in the range of $20-40 \mathrm{~nm}$ while that may higher up to $60 \mathrm{~nm}$ for $\mathrm{NiO}$ NPs. Further, on antimicrobial screening of Ni and NiONPs against Pseudomonas auruginosa, these were found equally potent, compared to Chloramphenicol.

\subsection{Titanium dioxide nanoparticles}

Infection by tick parasites like Rhipicephalus microplus and Haemaphysalis bispinosa is major hindrance in having and sustaining new generations of cattle. To have a scientific check for hypothesis that titanium dioxide nanoparticles $\left(\mathrm{TiO}_{2} \mathrm{NPs}\right)$ could be exhibiting significant 
acaricidal activity, Marimuthu et al. [36] attempted the green synthesis of $\mathrm{TiO}_{2}$ NPs using aqueous extract $C$. gigantea flowers and morphologically characterised. XRD pattern of $\mathrm{TiO}_{2}$ NPs showed diffraction peaks at $2 \theta$ values of $27.33^{\circ}, 35.83^{\circ}, 43.87^{\circ}, 54.02^{\circ}, 56.39^{\circ}, 66.64^{\circ}$ and $74.07^{\circ}$ could be assigned to the (110), (101), (210), (211), (220), (301) and (320), respectively; indicating faced centre cubic lattice structure of $\mathrm{TiO}_{2}$ NPs. SEM showed their spherical shape with particle size ranging between 160 and $220 \mathrm{~nm}$ [36]. also evaluated $\mathrm{TiO}_{2} \mathrm{NPs}$ against $R$. microplus and $H$. bispinosa by filter paper impregnated bioassay protocol. Researchers found that $\mathrm{LC}_{50}$ values shown by aqueous extract of flowers and $\mathrm{TiO}(\mathrm{OH})_{2}$ solution are around four times higher than those shown by $\mathrm{TiO}_{2} \mathrm{NPs}$, indicating $\mathrm{TiO}_{2} \mathrm{NPs}$ can be used to treat the tick parasitic infection in cattle.

\subsection{Cupric oxide nanoparticles}

To fulfil the increasing demands for energy, the development of photovoltaic technology especially, dyesensitised solar cells (DSSCs) are getting importance and research interest. Cupric oxide $(\mathrm{CuO})$ is a p-type semiconductor with narrow bandgap (Eg $1.2 \mathrm{eV}$ ) and material for the fabrication of various electronic and optoelectronic devices [37]. Therefore, in the fabrication of DSSCs, $\mathrm{CuO}$ NPs have been considered as an alternative counter electrode material. $\mathrm{CuO}$ NPs can also be used in making high-temperature superconductors [38] gas sensors [39] and giant magnetoresistance materials [40]. When incorporated into coatings, plastics and textiles,
$\mathrm{CuO}$ NPs acts as anti-fouling and antimicrobial [41]. Considering these technical applications, Sharma et al. [42], synthesised $\mathrm{CuO}$ NPs from Cupric Nitrate added to aqueous extract of $C$. gigantea leaves and fabricated $\mathrm{CuO}$ nanoparticles based counter electrode that to be used in DSSC. Initially, the formation of nanostructures was confirmed by the increased bandgap of $1.86 \mathrm{eV}$. In XRD analysis, several intense peaks at $2 \theta$ values of 32.4 , $35.5,38.7,48.7,53.4,58.3,61.5,66.2,68.0,72.4$ and $75.2^{\circ}$, were obtained, which could be assigned to (110), (002), (111), (202), (020), (202), (113), (311), (113), (311) and (222), respectively; indexing as typical monoclinic structure of CuO NPs. TEM analysis revealed the spherical shape of $\mathrm{CuO}$ NPs with a particle size up to $20 \mathrm{~nm}$. The cyclovoltametric measurement exposed that $\mathrm{CuO}$ NPs-based material showed to be a reasonably good platform for the reduction of triiodide ions in redox electrolyte, signifying its good electrocatalytic activity towards the iodide ions (Fig. 2). Kumari et al. [43] attempted synthesis of $\mathrm{CuO}$ NPs by the addition of floral extract of C. gigantea to $1 \mathrm{mM} \mathrm{CuCl}$ solution and characterised by advanced techniques. The hydrodynamic diameter of synthesised $\mathrm{CuO}$ NPs showed the diameter of $109 \pm 11 \mathrm{~nm}$. The zeta potential of $\mathrm{CuO}$ NPs was found to be $-34 \pm 12 \mathrm{mV}$. The XRD peaks were observed at $2 \theta$ values of $32.5,35.5,38.7,48.7,53.0,58.2$, $63.4,66.2$ and 68.1 corresponding to (110), (002), (111), (202), (020), (202), (113), (311) and (113), respectively. The result indicated a typical monoclinic structure of $\mathrm{CuO}$ NPs [43]. also explained the mechanism of



Fig. 2 Cupric oxide nanoparticles (CuO NPs) employed in dye-sensitized solar cells (DSSCs) 
biosynthesis of $\mathrm{CuO}$ NPs, according to which phytochemicals having hydroxyl groups played a significant role in reducing copper (II) chloride to copper hydroxide $\left(\mathrm{Cu}(\mathrm{OH})_{2}\right)$. Further, $\mathrm{Cu}(\mathrm{OH})_{2}$ got reduced to $\mathrm{CuO}$ NPs which were capped and stabilised by phytochemicals present in the floral extract of C. gigantea extracted in an aqueous medium.

$$
\begin{gathered}
\left.\mathrm{CuCl}_{2} .2 \mathrm{H}_{2} \mathrm{O}+2 \text { (Phytochemical }\right) \mathrm{OH} \rightarrow \mathrm{Cu}(\mathrm{OH})_{2} \\
+2(\mathrm{Phytochemical}) \mathrm{Cl} \\
+4 \mathrm{H}_{2} \mathrm{OCu}(\mathrm{OH})_{2} \rightarrow \mathrm{CuONPs}(\text { Cappedandstabilised }) \\
+\mathrm{H}_{2} \mathrm{O}
\end{gathered}
$$

The toxicity of $\mathrm{CuO}$ NPs was evaluated by determining their effect on physiological and morphological changes in Zebrafish embryo. Surprisingly, the hatching rate was found higher in the case of embryos exposed to $\mathrm{CuO} \mathrm{NPs}$ as compared to the commercial one. It was also observed that $\mathrm{CuO}$ NPs got accumulated at chorion, yolk sac and skin surface of 24, 48 and $72 \mathrm{~h}$ post-fertilization (hpf).

To determine the effect of synthesised $\mathrm{CuO}$ NPs in Zebrafish embryos at the cellular level, ROS induction and apoptosis were analysed in embryos after $72 \mathrm{hpf}$ of treatment with the help of flow cytometry and Acridine orange staining-based fluorescent microscopy.

\subsection{Zinc oxide nanoparticles}

Two successful attempts were made for green synthesis of zinc oxide nanoparticles ( $\mathrm{ZnO} \mathrm{NPs}$ ) using $C$. gignatea. Vidya et al. [44] used aqueous extract of $C$. gignatea leaves. They got hexagonal $\mathrm{ZnO}$ NPs ranging in size of 30-35 nm. Panda et al. [45] employed milky latex obtained by making an incision on the intact branches of C. gignatea and precursor zinc acetate; and carried out alkaline precipitation method. XRD pattern showed 13 characteristic diffraction peaks of (100), (002), (101), (102), (110), (103), (200), (112), (201), (004), (202, 104) and (203), observed at $2 \theta$ angles; $31.77^{\circ}, 34.42^{\circ}, 36.25^{\circ}$, $47.54^{\circ}, 56.6^{\circ}, 62.86^{\circ}, 66.38^{\circ}, 67.96^{\circ}, 69.09^{\circ}, 72.56^{\circ}, 76.95^{\circ}$, $81.37^{\circ}$ and $89.6^{\circ}$, respectively, reflecting wurtzite crystalline structure of $\mathrm{ZnO}$ NPs. C. gigantea milky latex-based $\mathrm{ZnO}$ NPs induced oxidative stress in DNA damage as determined by Comet assay in the root assay system of L. sativus, which was found comparable to that induced by the commercially available ZnO NPs-S (S for SigmaAldrich, St. Louis, MO, USA).

\subsection{Silver nanoparticles}

Rajkuberan et al. [46] synthesised silver nanoparticles (AgNPs) using freshly collected milky white latex of $C$. gigantea. Latex was first converted to $3 \%$ aqueous extract and then about $1 \mathrm{ml}$ was added to $9 \mathrm{ml}$ of $2 \mathrm{mM}$ silver nitrate, $\mathrm{AgNO}_{3}$. Then, AgNps were characterised by UV-Vis absorbance spectroscopy, FTIR analysis, Xray diffraction, FeSEM and TEM techniques; and evaluated for their antibacterial activity against Shigella and $P$. aeruginosa; and cytotoxicity against HeLa cells. XRD pattern showed diffraction peaks at (111), (101), (103) and (105) corresponded to $2 \theta$ values of $38.12,47.08$, 57.93 and $76.71^{\circ}$, respectively depicted that AgNPs had mixed phase of cubic and hexagonal structures. As per Debye-Scherrrer's equation, the average particle size was calculated as $12 \mathrm{~nm}$. About antimicrobial activity, it was observed that zone of inhibition created by lowest concentration $10 \mu \mathrm{l}$ of AgNPs was 2 to 3 times higher in diameter than those created by $3 \%$ aqueous latex extract. Cytotoxicity exerted by these AgNPs against HeLa cells was also significant with $\mathrm{LC}_{50}$ of $91.3 \mu \mathrm{g}$; however, that with $3 \%$ aqueous latex extract was found to be $311 \mu \mathrm{g}$.

\subsection{Iron oxide nanoparticles and biomaterial-supported zero-valent iron nanoparticles}

Jain et al. [47] employed aqueous extract of C. gigantea for phytofacation of iron oxide nanoparticles. The XRD pattern of the product can be clearly pointed to the facecentered cubic spine structure of iron oxide nanoparticles with a lattice parameter of $a=8.393 \AA$ and a size ranging between 3 and $6 \mathrm{~nm}$; exposing that reduction of $\mathrm{Fe}^{3+}$ by C. gigantea aqueous extract leads to $\mathrm{FeO}$ NPs as the final product. Further, in 2018, zero-valent iron nanoparticles (ZVIN) were synthesised by green ecofriendly method using aqueous extract of $C$. gigantea flowers and characterised by UV-Vis, FT-IR, XRD, SEM, and EDX [48]. The ZVIN so synthesised were spherical in shape and $50-90 \mathrm{~nm}$ in size. From the FT-IR and UVvisible spectrum, Sravanthi et al. 2018 concluded that polyphenols present in the flower extract were responsible for the reduction and stabilization of ZVIN. Then, they proved the effectivity of ZVIN in controlling water pollution by adsorptive removal of organic waste such as methylene blue (synthetic dye) (Fig. 3) and aniline (aromatic primary amine) from contaminated water.

\subsection{Tin oxide/stannic oxide nanoparticles}

Tin oxide/stannic oxide $\left(\mathrm{SnO}_{2}\right)$ is one of the n-type semiconductor having a bandgap of $3.6 \mathrm{eV}$, thereby used in photoconductive and photochemical device in liquid crystal display and lithium-ion batteries; and transparent conductive electrode for solar cells, gas sensors [49]. Because of the high surface to volume ratio, $\mathrm{SnO}_{2} \mathrm{NPs}$ exhibit increased sensitivity and adsorption and can be used as photocatalyst [50]. Considering this significance, Bhosale et. al. [51] attempted the green synthesis of $\mathrm{SnO}_{2} \mathrm{NPs}$ by the addition of dilute aqueous extract of leaves to $0.05 \mathrm{M}$ solution of tin chloride $\left(\mathrm{SnCl}_{4} \cdot 5 \mathrm{H}_{2} \mathrm{O}\right)$ with constant stirring. They claimed that tin chloride reacted with polyphenols present in the extract and 

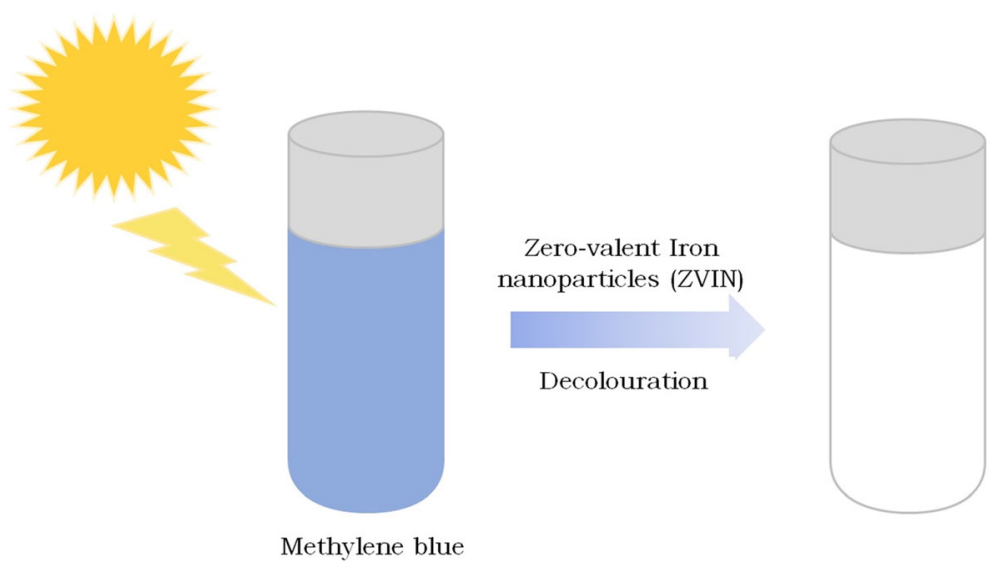

Fig. 3 Use of zero-valent iron nanoparticles (ZVIN) photocatalytic decolouration of dye methylene blue

following calcination, they got $\mathrm{SnO}_{2}$ NPs with spherical morphology of an average size of $35 \mathrm{~nm}$. In XRD pattern, the peaks at $2 \theta$ values of $26.5^{\circ}, 34^{\circ}, 37.9^{\circ}, 51.7^{\circ}$, $54.4^{\circ}, 57.7^{\circ}, 61.7^{\circ}, 64.8^{\circ}, 71.3^{\circ}$ and $78.5^{\circ}$ were associated with (110), (101), (200), (211), (220), (002), (310), (301), (202) and (222) planes, respectively, proving the formation of $\mathrm{SnO}_{2}$ NPs with tetragonal structure. Then, Bhosale et al. 2018 also explained the plausible mechanism for the formation of $\mathrm{SnO}_{2} \mathrm{NPs}$, according to which $\mathrm{SnCl}_{4} \cdot 5 \mathrm{H}_{2} \mathrm{O}$ salt solution on mixing with C. gigantea leaf extract, $\mathrm{Sn}^{4+}$ ions form a complex with hydroxyl groups. The complex so formed got decomposed on calcination. Polyphenolic molecules then kept $\mathrm{Sn}^{4+}$ cations together forming $\mathrm{SnO}_{2}$ NPs. Taking dye methyl orange as a model pollutant under UV-light, its degradation was further tested as a function of photocatalytic potential of the synthesised $\mathrm{SnO}_{2}$ NPs (Fig. 4).

\section{$2.14 \mathrm{Eu}_{3}{ }^{+}$doped $\mathrm{Y}_{2} \mathrm{SiO}_{5}$ nanophosphors}

During the last decade, white light-emitting diodes (WLEDs), due to high efficiency, energy-saving, long lifetime, safety and environmental protection have fascinated a lot of research interest in the solid-state lighting [52]. White light was obtained by the foremost technique involving the mixing ultraviolet (UV) LED chip with tricolour phosphors [53] but the lack of appropriate red phosphors decreased colour rending index (CRI). So far newly designed red phosphor, $\mathrm{Y}_{2} \mathrm{O}_{2} \mathrm{~S}$ : $\mathrm{Eu}^{+}$has shown low efficiency and poor chemical stability. Therefore, Ramakrishna et al. [54] accepted this challenge of developing a new red phosphor with sufficiently high luminous efficiency and fabricated red-emitting Eu3+ doped $\mathrm{Y}_{2} \mathrm{SiO}_{5}$ nanophosphors using C. gigantea latex, Yttrium nitrate $\left(\mathrm{Y}\left(\mathrm{NO}_{3}\right)_{3}\right.$, Europium nitrate $\left(\mathrm{Eu}\left(\mathrm{NO}_{3}\right)_{2}\right.$, $\mathrm{H}_{2} \mathrm{O}$ and $\mathrm{NaCl}$. The Eu3+ doped $\mathrm{Y}_{2} \mathrm{SiO}_{5}$ nanophosphors so obtained were irregular shape with an average size of $32 \mathrm{~nm}$ which was found decreasing on the increasing concentration of $\left(\mathrm{Eu}\left(\mathrm{NO}_{3}\right)_{2}\right.$. Determination of optical properties of Eu3+ doped $\mathrm{Y}_{2} \mathrm{SiO}_{5}$ nanophosphors was based on emission spectra and Judd-Ofelt theory. It was observed that there is ionic bonding between Eu3+ ions and host; and assembled in symmetrical in coordination

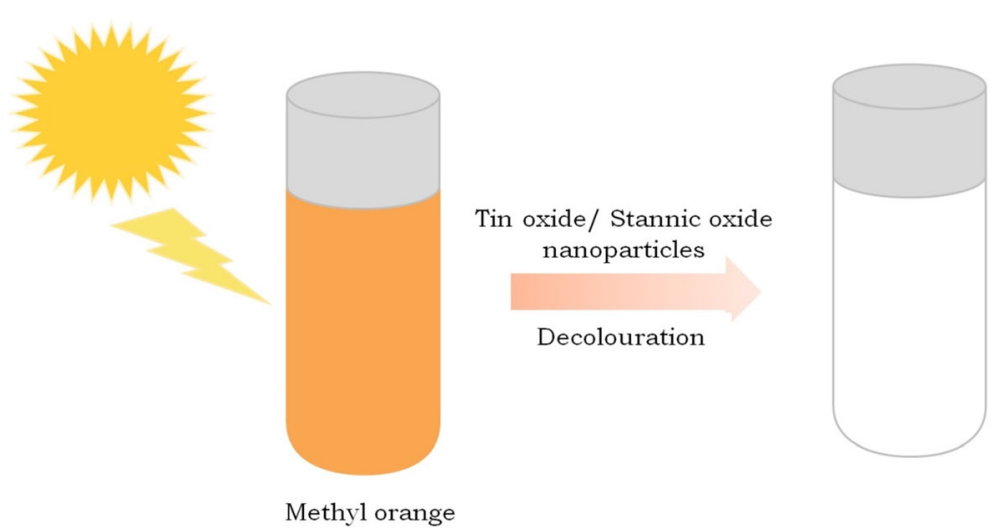

Fig. 4 Use of tin oxide/stannic oxide nanoparticles photocatalytic decolouration of dye methyl orange 


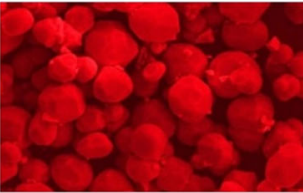

$\mathrm{Eu}^{3+}$ doped $\mathrm{Y}_{2} \mathrm{SiO}_{5}$ nanophosphors



Chromaticity

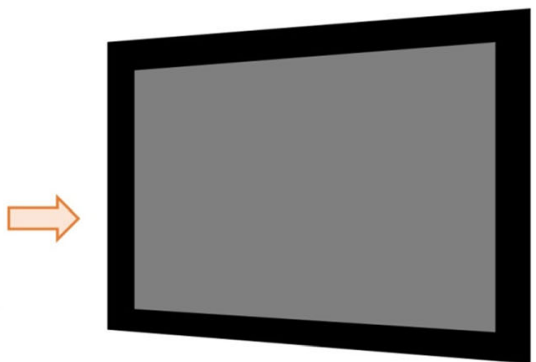

Light Emitting Diodes (LEDs)

Fig. 5 Application of Eu3+ doped $\mathrm{Y}_{2} \mathrm{SiO}_{5}$ nanophosphors that can used in light-emitting diodes (LEDs)

structure surrounding the (rare earth) RE ion. This newly synthesised phosphor exhibited admirable International Commission on Illumination (CIE) chromaticity coordinates $(0.5866,4026)$ and average correlated colour temperature CCT value $2018.5 \mathrm{~K}$. Hence, researchers claimed that these Eu3+ doped $\mathrm{Y}_{2} \mathrm{SiO}_{5}$ nanophosphors could have potential application in the fabrication of nearultraviolet excited white light-emitting diodes (Fig. 5).

\section{Conclusion}

Calotropis gigantea (Asclepiadeae) is the plant having several well-proved pharmacological actions. Several types of nanomaterials have been synthesised following green approach using aqueous extract of different parts of C. gigantea; evaluated for different pharmacological activities and potential were compared that with extracts. Nanomaterials tried to get synthesised include nanoparticles and nanophophors. Importantly, green synthesis of nanoparticles has upsurge as new nanobiotechnology to produce eco-friendly and cost-effective synthetic processes for highly stable nanoparticles which emerges as a safer alternative to conventional methods. These nanoparticles were proved to have better antimicrobial action against both animal and plant infecting pathogens and utilities in controlling the water pollution by adsorbing or precipitating pollutants, demonstrated using dyes and other organic compounds. Nanophosphors have been extensively investigated during the last decade due to their application potential for various high-performance displays and devices.

\footnotetext{
Abbreviations

Ag NPs: Silver nanoparticles; CCT: Correlated colour temperature; CdS NPs: Cadmium sulphide nanoparticles; CRI: Colour rending index; CuO NPS: Cupric oxide nanoparticles; FT-IR: Fourier transform-infrared spectroscopy; Ni-NPs: Nickel nanoparticles; NiO-NPs: Nickel oxide nanoparticles; SEM: Scanning electron microscopy; $\mathrm{SnO}_{2}$ NPs: Tin oxide/stannic oxide nanoparticles; TEM: Transmission electron microscopy; $\mathrm{TiO}_{2} \mathrm{NPS}$ : Titanium dioxide nanoparticles; XRD: X-ray diffraction; ZnO NPs: Zinc oxide nanoparticles; ZVIN: Zero-valent iron nanoparticles
}

\section{Acknowledgements}

The author of this manuscript is thankful to Dr(Mrs.) Anagha M. Joshi, Principal, SCES's Indira College of Pharmacy, Pune, for her encouragement and also for providing internet and library facilities at the college premises to access the articles and books to carry out this review.

\section{Author's contributions}

SPP initiated the idea of designing this review, carried out the survey of the available literature and written the review manuscript. The author read and approved the final manuscript.

\section{Authors' information}

Mr. Shriniwas P. Patil has completed his M. Pharm with specialisation in Pharmacognosy in 2012. He has received Senior Research Fellowship for the project entitled, 'Quality standards of Indian Medicinal Plants and preparation of monographs thereon' sponsored by Indian Council of Medical Research, ICMR- New Delhi, India. He has several research articles pertaining to phytochemistry and pharmacology of medicinal plant to his credit. He has been recognised as reviewer for research articles to be published in International peer-reviewed journal groups. Currently, he is serving as Assistant Professor at SCES's Indira College of Pharmacy, Pune, affiliated to Savitribai Phule Pune University, SPPU (formerly University of Pune).

Funding

Not applicable

Availability of data and materials Not applicable

Ethics approval and consent to participate Not applicable

\section{Consent for publication}

Not applicable

\section{Competing interests}

The authors declare that they have no competing interests.

Received: 31 August 2019 Accepted: 15 January 2020

Published online: 01 April 2020

\section{References}

1. Antonietti M (2016) Small is beautiful: challenges and perspectives of nano/ meso/microscience. Small. 12(16):2107-114

2. Na Y, Yang S, Lee S (2014) Evaluation of citrate-coated magnetic nanoparticles as draw solute for forward osmosis. Desalination 347:34-42

3. Davar F, Fereshteh Z, Salavati-Niasari M (2009) Nanoparticles Ni and NiO: synthesis, characterization and magnetic properties. J Alloys Compd 476(12):797-801

4. Kreyling WG, Semmler-Behnke M, Chaudhry Q (2010) A complementary definition of nanomaterial. Nano Today 5(3):165-168

5. Krishnamurthy N, Vallinayagam P, Madhavan D (2014) Engineering chemistry. PHI Learning Pvt Ltd, Delhi

6. Rahman MA, Wilcock CC (1991) A taxonomic revision of Calotropis (Asclepiadaceae). Nord J Bot 11(3):301-308 
7. Lhinhatrakool T, Sutthivaiyakit S (2006) 19-nor- and 18, 20epoxycardenolides from the leaves of Calotropis gigantea. J Nat Prod 69: 1249-1251

8. Seeka C, Sutthivaiyakit S (2010) Cytotoxic Cardenolides from the leaves of Calotropis gigantea. Chem Pharm Bull 58(5):725-728

9. Nguyen $\mathrm{KDH}$, Dang PH, Nguyen HX, Nguyen MTT, Awale S, Nguyen NT (2017) Phytochemical and cytotoxic studies on the leaves of Calotropis gigantea. Bioorg Med Chem Lett 27:2902-2906

10. Habib MR, Karim MR (2009) Antimicrobial and cytotoxic activity of Di-(2ethylhexyl) phthalate and anhydrosophoradiol-3-acetate isolated from Calotropis gigantea (Linn.) flower. Mycobiology 37(1):31-36

11. Sen S, Sahu NP, Mahato SB (1992) Flavonol glycosides from Calotropis gigantean. Phytochemistry 31(8):2919.2921

12. Lakshminarayana G, Rao KS, Pantulu AJ, Gupta DR (1988) Surface and Internal Lipids of Calotropis gigantea L. Leaves. Fat Sci Technol 90(Jahrgang Nr.2):65-67

13. Ali M.; Gupta J; Indian J. Chem., Sect. B: Org. Chem. Incl. Med. Chem. 38 (1999) 7, 877-881;

14. Kadiyal M, Ponnusankar S, Elango K (2013) Calotropis gigantiea (L.) R. Br (Apocynaceae): a phytochemical and pharmacological review. J Ethnopharmacol 150(1):32-50

15. Pathak AK, Argal A (2007) Analgesic activity of Calotropis gigantea flower. Fitoterapia 78:40-42

16. Habib MR, Karim MR (2013) Effect of anhydrosophoradiol-3-acetate of Calotropis gigantea (Linn.) flower as antitumoric agent against Ehrlich's ascites carcinoma in mice. Pharmacol Rep 65:761-767

17. Ishnava KB, Chauhan JB, Garg AA, Thakkar AM (2012) Antibacterial and phytochemical studies on Calotropis gigantia (L.) R. Br. Latex against selected cariogenic bacteria. Saudi J Biol Sci 19:87-91

18. Pattnaik PK, Dattatreya KD, Chhatoi H, Shahbazi S, Ghosh G, Kuanar A (2017) Chemometric profile \& antimicrobial activities of leaf extract of Calotropis procera and Calotropis gigantea. Nat Prod Res 31(16):1954-1957

19. Chitme HR, Chandra R, Kaushik S (2005) Evaluation of antipyretic activity of Calotropis gigantea (Asclepiadaceae) in experimental animals. Phytother Res 19:454-456

20. Habib MR, Karim MR (2011) Evaluation of antitumour activity of Calotropis gigantea L. root bark against Ehrlich ascites carcinoma in Swiss albino mice. Asian Pac J Trop Med 4:786-790

21. Argal A, Pathak AK (2006) CNS activity of Calotropis gigantea roots. J Ethnopharmacol 106:142-145

22. Ghule SD, Vidyasagar G, Bhandari A, Sharma P, Gunjal AP (2014) CNS activity of leaves extract of Calotropis gigantea. Asian Pac J Trop Dis 4(Suppl 2): S902-S905

23. Taylor P, Arsenak M, Abad MJ, Fernández A, Milano B, Gonto R, Ruiz MC, Fraile S, Taylor S, Estrada O, Michelangeli F (2012) Screening of Venezuelan medicinal plant extracts for cytostatic and cytotoxic activity against tumor cell lines. Phytother Res 24(4):530-539

24. Wong SK, Lim YY, Abdullah NR, Nordin FJ (2011) Assessment of antiproliferative and antiplasmodial activities of five selected Apocynaceae species. BMC Complement Altern Med 11(3):1-8

25. Parhira S, Zhu G, Chen M, Bai L, Jiang Z (2016) Cardenolides from Calotropis gigantea as potent inhibitors of hypoxiainducible factor-1 transcriptional activity. J Ethnopharmacol 194:930-936

26. Deshmukh PT, Fernandes J, Akarte A, Toppo E (2009) Wound healing activity of Calotropis gigantea root bark in rats. J Ethnopharmacol 125:178-181

27. Srivastava SR, Keshri G, Bhargavan B, Singh C, Singh MM (2007) Pregnancy interceptive activity of the roots of Calotropis gigantea Linn. In rats. Contraception 75:318-322

28. Rajesh R, Gowda CDR, Nataraju A, Dhananjaya BL, Kemparaju K, Vishwanath BS (2005) Procoagulant activity of Calotropis gigantea latex associated with fibrin (ogen) olytic activity. Toxicon 46:84-92

29. Ayodhya D, Veerabhadram G (2017) One-pot green synthesis, characterization, photocatalytic, sensing and antimicrobial studies of Calotropis gigantea leaf extract capped CdS NPs. Mat Sci Engineering B 225:33-44

30. Hii YS, Jaison Jeevanandam J, San Chan YS (2018) Plant mediated green synthesis and nanoencapsulation of $\mathrm{MgO}$ nanoparticle from Calotropis gigantea: Characterisation and kinetic release studies. Inorg Nano-Met Chem 48 (2018):620-31

31. Pandian CJ, Palanivel R, Dhananasekaran S (2015) Green synthesis of nickel nanoparticles using Ocimum sanctum and their application in dye and pollutant adsorption. Chin J Chem Eng 23(8):1307-1315
32. Angajala G, Radhakrishnan S (2014) A review on nickel nanoparticles as effective therapeutic agents for inflammation. Inflamm Cell Signal 1(3):1-8

33. Thema F, Manikandan E, Gurib-Fakim A, Maaza M (2016) Single phase Bunsenite $\mathrm{NiO}$ nanoparticles green synthesis by Agathosma betulina natural extract. J Alloys Compd 657:655-661

34. Borgström M, Blart E, Boschloo G, Mukhtar E, Hagfeldt A, Hammarström L, Odobel F (2005) Sensitized hole injection of phosphorus porphyrin into NiO: toward new photovoltaic devices. J Phys Chem B 109(48):22928-34

35. Din Ml, Nabi AG, Rani A, Aihetasham A, Mukhtar M (2018) Single step green synthesis of stable nickel and nickel oxide nanoparticles from Calotropis gigantea: catalytic and antimicrobial potentials. Environ Nanotechnol Monit Manag 9:29-36

36. Marimuthu S, Rahuman AA, Jayaseelan C, Kirthi AV (2013) Acaricidal activity of synthesized titanium dioxide nanoparticles using Calotropis gigantea against Rhipicephalus microplus and Haemaphysalis bispinosa. Asian Pac J Trop Med 6:682-688

37. Kumar RV, Elgamiel R, Diamant Y, Gedanken A, Norwig J (2001) Langmuir 17:1406-1410

38. Malandrino G, Condorelli GG, Lanza G, Fragala IL, Alloys J (1997) Compd 251:314-316

39. Ishihara T, Higuchi M, Takagi T, Ito M, Nishiguchi H, Takita T (1998) J Mater Chem 8:2037-2042

40. Liu X, Bi N, Feng C, Or SW, Sun Y, Jin C, Li W, Xiao F, Alloys J (2014) Comp $587: 1-5$

41. Apostolov AT, Apostolova IN, Wesselinowa JM (2014) Solid State Commun 192:71-74

42. Sharma JK, Akhtar MS, Ameen S, Srivastava P, Singh G (2015) Green synthesis of $\mathrm{CuO}$ nanoparticles with leaf extract of Calotropis gigantea and its dye-sensitized solar cells applications. J Alloys Compd 632:321-325

43. Kumari P, Panda PK, Jha E, Kumari K, Nisha K, Mallick MA, Verma SK (2017) Mechanistic insight to ROS and Apoptosis regulated cytotoxicity inferred by green synthesized $\mathrm{CuO}$ nanoparticles from Calotropis gigantea to embryonic Zebrafish. Sci Rep 7:16284

44. Vidya C, Hiremath S, Chandraprabha MN, Antonyraj MAL, Venu Gl, Jain A, Kokil BK (2013) Green synthesis of ZnO nanoparticles by Calotropis gigantea. Int J Curr Engineering Technol (1):118-20

45. Panda KK, Golari D, Venugopal A, Achary VMM, Phaomei G, Parinandi NL, Sahu HK, Panda BB (2017) Green synthesized zinc oxide (ZnO) nanoparticles induce oxidative stress and DNA damage in Lathyrus sativus L. Root Bioassay System. Antioxidants 6:35

46. Rajkuberan C, Sudha K, Sathishkumar G, Sivaramakrishnan S (2014) Antibacterial and cytotoxic potential of silver nanoparticles synthesized using latex of Calotropis gigantea L. Spectrochimica Acta Part A: Mol Biomol Spectroscopy 136B:924-30

47. Jain D, Rathore KS, Jain R, Singh H, Kachhwaha S, Kothari SL (2013) Phytofabrication of Iron oxide nanoparticles using Calotropis gigantea L. Adv Sci Focus 4(1):318-321

48. Sravanthi K, Ayodhya D, Swamy PY (2018) Green synthesis, characterization of biomaterial-supported zero-valent iron nanoparticles for contaminated water treatment. J Analytical Sci Technol 9:3

49. Naje AN, Norry AS, Suhail AM (2013) IJIRSET 2:7068

50. Suwarnkar MB, Kadam AN, Khade GV, Gavade NL, Garadkar KM (2016) J Mater Sci Mater Electron 27:843

51. Bhosale TT, Shinde HM, Gavade NL, Babar SB, Gawade W, Sabale SR, Kamble RJ, Shirke BS, Garadkar KM (2018) Biosynthesis of $\mathrm{SnO}_{2}$ nanoparticles by aqueous leaf extract of Calotropis gigantea for photocatalytic applications. J Mater Sci. volume 8

52. Yu R, Noh H, Moon B, Choi B, Jeong, Lee H, Jang K, Yi S (2014) J Lumin 145 $717-722$

53. Liang CH, Chang YC, Chang YS (2008) Appl Phys Lett 93:211902

54. Ramakrishna G, Nagabhushana H, Daruka PD, Vidya YS, Sharma SC, Anantharaju KS, Prashantha SC, Choudhary N (2016) Spectroscopic properties of red emitting Eu3+ doped $\mathrm{Y}_{2} \mathrm{SiO}_{5}$ nanophosphors for WLED's on the basis of Judd-Ofelt analysis: Calotropis gigantea latex mediated synthesis. J Lumin 181:153-63

\section{Publisher's Note}

Springer Nature remains neutral with regard to jurisdictional claims in published maps and institutional affiliations. 